\title{
Ueber den Cyanuräther;
}

\section{von H. Limpricht.}

Vor 8 Jahren begann ich eine Untersuchung des von Wurt $z$ entdeckten Cyanuräthers, die theils aus Mangel an Material, theils aus anderen Gründen nicht zu Ende geführt wurde. Ein Theil der von mir gewonnenen Resultale wurde im Bd. LXXIV, S. 208 dieser Annalen veröffentlicht, namentlich eines sehr schön krystallisirten Körpers $\mathrm{C}_{14} \mathrm{H}_{11} \mathrm{~N}_{3} \mathrm{O}_{6}$ (Biällyylcyanursäure $\underset{\left.\left(\mathrm{C}_{4} \mathrm{H}_{5}\right)_{2} \mathrm{H}\right\}}{\mathrm{C}_{6} \mathrm{~N}_{8}} \mathrm{O}_{6}$ ) Erwähnung gethan. Ich habe die Untersuchung des Cyanuräthers von Herrn Habich wieder aufnehmen lassen und gebe hier eine vorläufige Notiz der schon festgestellten Thatsachen.

Der Cyanuräther, $\mathrm{C}_{18} \mathrm{H}_{15} \mathrm{~N}_{3} \mathrm{O}_{6}$, wurde durch Destillation des cyanursauren Kali's mit ätherschwefelsaurem Kali dargestellt. Beim Kochen mit Alkalien zerfällt er nicht sogleich in Kohlensäure und Aethylamin, sondern es treten noch Zwischenproducte auf. Wird mit Barytwasser gekocht, so scheidet sich kohlensaurer Baryt aus, ohne dafs Ammoniak oder Aethylamin durch den Geruch zu entdecken sind; nach halbstündigem Kochen wird der noch in Lösung befindliche Baryt mit Kohlensäure ausgefällt und die vom kohlensauren Baryt filtrirte Flüssigkeit im Wasserbade verdunstet. Es bleibt ein in Wasser schwer, in Weingeist leicht löslicher Syrup von der Zusammenselzung $\mathrm{C}_{16} \mathrm{H}_{17} \mathrm{~N}_{3} \mathrm{O}_{4}$, der nach der folgenden Gleichung aus dem Cyanuräther entstebt :

$$
\mathrm{C}_{18} \mathrm{H}_{15} \mathrm{~N}_{5} \mathrm{O}_{6}+2 \mathrm{HO}=\mathrm{C}_{16} \mathrm{H}_{17} \mathrm{~N}_{3} \mathrm{O}_{4}+\mathrm{C}_{2} \mathrm{O}_{4}
$$

Cyanuräther.

Diese syruparlige Verbindung zerlegt sich bei der Destillation in einer kleinen Retorte in Diäthylharnstoff und Cyansäureäther : 


$$
\begin{aligned}
& \mathrm{C}_{16} \mathrm{H}_{17} \mathrm{~N}_{3} \mathrm{O}_{4}=\mathrm{C}_{6} \mathrm{H}_{5} \mathrm{NO}_{2}+\mathrm{C}_{10} \mathrm{H}_{12} \mathrm{~N}_{2} \mathrm{O}_{2} \\
& \text { Cyansăureäther Diâthylharnstoff. }
\end{aligned}
$$

Der Diäthylharnstoff endlich zerfält beim Behandeln mit trockenem Salzsäuregas und darauf folgender Destillation in salzsaures Aethylamin und salzsauren Cyansäureäther :

$$
\underset{\text { Diäthylharnstoff }}{\mathrm{C}_{10} \mathrm{H}_{12} \mathrm{~N}_{2} \mathrm{O}_{2}}+2 \mathrm{HCl}=\underset{\substack{\text { Salzsaurer Cyansäure- } \\ \text { âther }}}{\mathrm{C}_{6} \mathrm{H}_{5} \mathrm{NO}_{2}, \mathrm{HCl}}+\underset{\substack{\text { Salzsaures } \\ \text { Aethylamin. }}}{\mathrm{C}_{4} \mathrm{H}_{7} \mathrm{~N}, \mathrm{HCl}}
$$

Der salzsaure Cyansäureäther bildet sich auch aus trockenem Salzsäuregas und Cyansäureäther. $E r$ ist eine unzersetzt bei $95^{\circ}$ siedende Flüssigkeit, riecht penetrant und sein Dampf greift die Augen stark an; mit Wasser zerselzt er sich augenblicklich mit gröfster Heftigkeit in Koblensäire und salzsaures Aelhylamin :

$$
\mathrm{C}_{6} \mathrm{H}_{5} \mathrm{NO}_{2}, \mathrm{HCl}+2 \mathrm{HO}=\mathrm{C}_{2} \mathrm{O}_{4}+\mathrm{C}_{4} \mathrm{H}_{7} \mathrm{~N}, \mathrm{HCl} \text {. }
$$

Ausgegeben den 27. März 1858. 